\title{
polymers
}

ISSN 2073-4360

www.mdpi.com/journal/polymers

Article

\section{Synthesis and Properties of 1,8-Carbazole-Based Conjugated Copolymers}

\author{
Tsuyoshi Michinobu ${ }^{1,2, *}$, Haruka Osako ${ }^{1}$ and Kiyotaka Shigehara ${ }^{1}$
}

1 Graduate School of Engineering and Institute of Symbiotic Science and Technology, Tokyo University of Agriculture and Technology/2-24-16 Nakacho, Koganei, Tokyo 184-8588, Japan

2 Global Edge Institute, Tokyo Institute of Technology/2-12-1 Ookayama, Meguro-ku, Tokyo 152-8550, Japan

* Author to whom correspondence should be addressed; E-Mail: michinobu.t.aa@m.titech.ac.jp; Tel.: +81-3-5734-3774; Fax: +81-3-5734-3774.

Received: 28 June 2010; in revised form: 19 July 2010 / Accepted: 29 July 2010 /

Published: 30 July 2010

\begin{abstract}
A new series of conjugated carbazole polymers based on the 1,8-carbazolylene unit was synthesized by the Pd-catalyzed polycondensation between the 1,8-diiodocarbazole derivative and various bifunctional counter comonomers. An alkyne spacer was found to be a key to increasing the molecular weight of the resulting polymers. All the obtained polymers showed good solubilities in the common organic solvents, and they were fully characterized by Gel permeation chromatography (GPC), and ${ }^{1} \mathrm{H}$ NMR and infrared (IR) spectroscopies. The UV-vis absorption and fluorescence spectra revealed the relationship between the chemical structure and effective conjugation length. The efficiency order of the carbazole connectivity was 2,7-carbazolylene >1,8-carbazolylene > 3,6-carbazolylene. The electrochemical properties of these polymers suggested the relatively facile oxidation at $c a .+0.5-0.7 \mathrm{~V} v s . \mathrm{Fc} / \mathrm{Fc}^{+}$or a high potential as p-type semiconductors. The combination of the electrochemical oxidation potentials and the optical band gaps allowed us to estimate the HOMO and LUMO levels of the polymers. It was shown that the energy levels of the 1,8-carbazole-based conjugated polymers can be tunable by selecting the appropriate comonomer structures.
\end{abstract}


Keywords: carbazole; conjugated polymer; electrochemistry; UV-vis absorption

\section{Introduction}

In recent years, conjugated carbazole polymers have attracted increasing attention because of their strong fluorescence, excellent hole transporting ability, and the related application possibilities in organic electronic devices [1,2]. It is known that the connectivity of the carbazole moiety significantly affects the polymer properties. Poly(3,6-carbazole)s are an initially reported class of conjugated carbazole polymers, in which the highest electron density positions are connected either directly or through $\pi$-spacers (Figure 1) [3-5]. They are suitable for electrochemical and phosphorescent applications due to their relatively stable oxidized or excited states [6,7]. When an efficient synthetic route for achieving 2,7-dihalocarbazole derivatives was established [8,9], poly(2,7-carbazole)s emerged as an alternative to blue-light fluorescent polyfluorene derivatives, which possessed a photodegradation problem leading to a different color emission and optical instability [10,11]. Later, the conjugated copolymers of the electron-donating 2,7-carbazolylene and electron-accepting $\pi$-systems were found to be very suitable as a p-type semiconductor for bulk heterojunction solar cells [12-16]. These findings stimulated renewed interests in the development of conjugated carbazole polymers with different connectivities. For example, poly(2,9-carbazole)s and poly(3,9-carbazole)s were recently synthesized and their properties were comprehensively investigated [17-20].

In 2007, we started a project focused on carbazole polymers [21-24]. During the course of the study, we realized that the 1,8-positions of the carbazole had not been noted in polymer chemistry. Therefore, we designed some new poly(1,8-carbazole)s, e.g., alkyne-linked conjugated poly(1,8-carbazole)s, and it was found that these carbazole polymers possess characteristics of both the poly(3,6-carbazole)s and poly(2,7-carbazole)s, as revealed by the long wavelength absorption, strong fluorescence, and significant electrochemical activities [25,26]. To diversify the list of the promising poly(1,8-carbazole)s, we also reported the directly-linked poly(1,8-carbazole) [27]. In this paper, conjugated copolymers of 1,8-carbazolylene and various arylene units are reported. Their optical and electrochemical properties were investigated in detail and their chemical structure-property relationships are summarized.

Figure 1. Conjugated carbazole polymers with various connectivities.

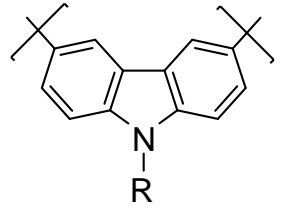

poly(3,6-carbazole)s

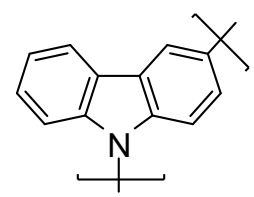

poly(3,9-carbazole)s

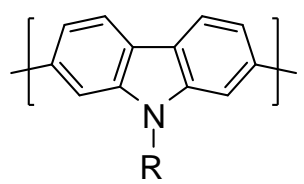

poly(2,7-carbazole)s

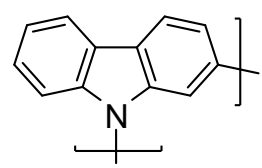

poly(2,9-carbazole)s

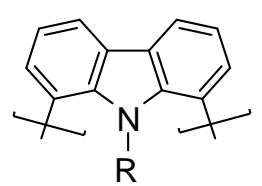

poly(1,8-carbazole)s 


\section{Results and Discussion}

\subsection{Polymer Synthesis}

A key monomer, the 1,8-diiodocarbazole derivative 1, was designed and synthesized according to a previous method [25]. The 3, 6, and 9 positions of the carbazole moiety were substituted by alkane groups in order to improve their chemical stability toward oxidation and solubility in organic solvents.

This bifunctional monomer was subjected to polycondensation with other bifunctional monomers under the Suzuki coupling conditions or the Sonogashira coupling conditions. In a typical Suzuki polycondensation procedure, a mixture of $\mathbf{1}$ and a bis-boronic ester functionalized comonomer in THF/aq. $\mathrm{K}_{2} \mathrm{CO}_{3}$ solution was heated under reflux for $72 \mathrm{~h}$ in the presence of $\mathrm{Pd}\left(\mathrm{PPh}_{3}\right)_{4}$. The previous synthesis of a directly-linked poly(1,8-carbazole) was based on the Yamamoto polycondensation of 1 [ $\mathrm{Ni}(\mathrm{cod})_{2}$, cod, bpy, DMF] [27]. In contrast to this method, which only produces homopolymers or random copolymers, the Suzuki polycondensation allows for the incorporation of various comonomers in an alternating sequence. Thus, copolymers P1-P3 were synthesized from $\mathbf{1}$ and different comonomers 2-4 (Scheme 1). The molecular weights of the resulting polymers were determined by Gel permeation chromatography (GPC) (Table 1). The results revealed the oligomeric molecular weights of these polymers, which are similar to previous reports [27]. This might be caused by unstable intermediates in the catalytic cycle, leading to the hydro-dehalogenated oligomers, or the steric hindrance of the long alkyl chain attached to the carbazole nitrogen.

Table 1. Summary of the polymerization results and thermal properties.

\begin{tabular}{ccccccc}
\hline Polymer & Yield $(\boldsymbol{\%})$ & $\boldsymbol{M}_{\mathbf{w}}{ }^{\mathbf{a}}$ & $\boldsymbol{M}_{\mathbf{n}}{ }^{\mathbf{a}}$ & $\boldsymbol{M}_{\mathbf{w}} / \boldsymbol{M}_{\mathbf{n}}{ }^{\mathbf{a}}$ & $\boldsymbol{T}_{\mathbf{5} \%}\left({ }^{\circ} \mathbf{C}\right)$ & $\boldsymbol{T}_{\mathbf{g}}\left({ }^{\mathbf{b}} \mathbf{C}\right)$ \\
\hline P1 & 28 & 1,400 & 1,300 & 1.1 & 259 & - \\
$\mathbf{P 2}$ & 61 & 1,700 & 1,400 & 1.2 & 276 & - \\
P3 & 15 & 2,000 & 1,800 & 1.1 & 276 & 63 \\
P4 & 99 & 6,900 & 4,300 & 1.6 & 340 & 77 \\
P5 & 100 & 13,000 & 7,200 & 1.8 & 380 & 80 \\
\hline
\end{tabular}

a Determined by GPC (THF eluent, calibrated by polystyrene standards).

b Temperature at which a $5 \%$ weight loss occurred upon heating.

c Glass transition temperature determined by the second heating scan of the DSC measurements.

It was previously shown that an alkyne spacer is effective for improving the molecular weights of the poly(1,8-carbazole)s [27]. Therefore, new alkyne-linked 1,8-carbazolylene-based copolymers were prepared from 1 and diethynylcarbazole derivatives 5/6 under the Sonogashira coupling conditions (Scheme 1). In these cases, the molecular weight $\left(M_{\mathrm{w}}\right)$ reasonably increased to 6900 for $\mathbf{P 4}$ and 13000 for P5.

The obtained polymers showed good solubilities in the common organic solvents as well as film formation capability. Therefore, they were fully characterized by NMR and Infrared (IR) spectroscopies. As an example, the ${ }^{1} \mathrm{H}$ NMR and IR spectra of $\mathbf{P 4}$ are shown in Figure 2. The ${ }^{1} \mathrm{H}$ NMR spectrum showed complex multiplet peaks in the aromatic region due to the two different connectivity modes of the carbazole unit. Alkyl peaks ascribed to the 3,6, and 9-positions of the carbazole unit were reasonably detected. The IR spectrum was consistent with these data. The C-H stretching 
vibration of the alkyl chains appeared in the range from 2953 to $2851 \mathrm{~cm}^{-1}$. Moreover, a very weak alkyne vibration peak ascribed to the $\mathrm{C} \equiv \mathrm{C}$ moieties was observed at $2199 \mathrm{~cm}^{-1}$.

Scheme 1. Synthesis of conjugated carbazole polymers. (a) $\mathrm{Pd}\left(\mathrm{PPh}_{3}\right)_{4}, \mathrm{THF}, 2 \mathrm{M}$ aq. $\mathrm{K}_{2} \mathrm{CO}_{3}, \Delta, 72$ h. (b) $\mathrm{PdCl}_{2}\left(\mathrm{PPh}_{3}\right)_{2}, \mathrm{CuI}$, toluene, $i \mathrm{Pr}_{2} \mathrm{NH}, \Delta, 24 \mathrm{~h}$.
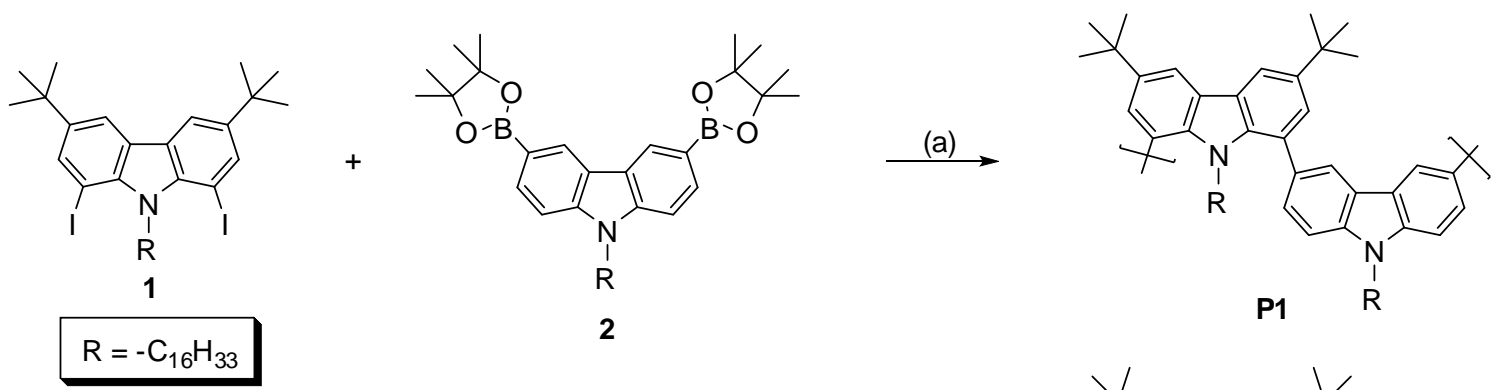

$1+$

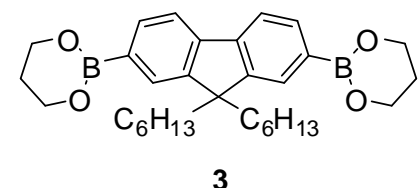

(a)

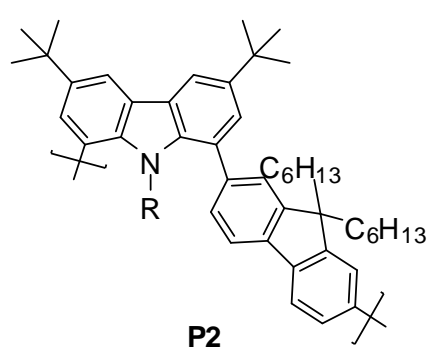

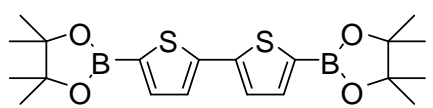

4
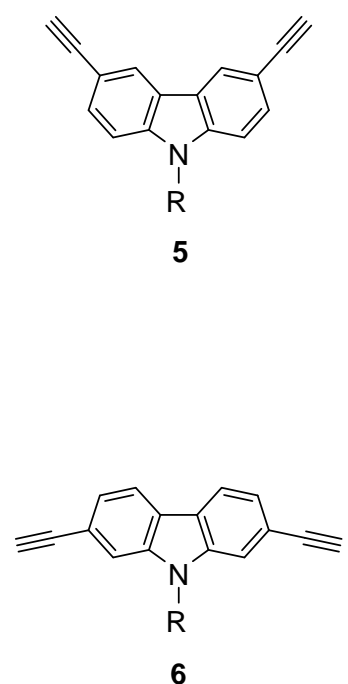

$\stackrel{(a)}{\longrightarrow}$

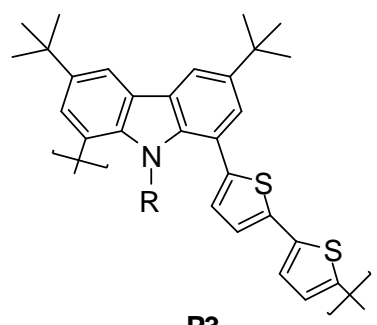

P3
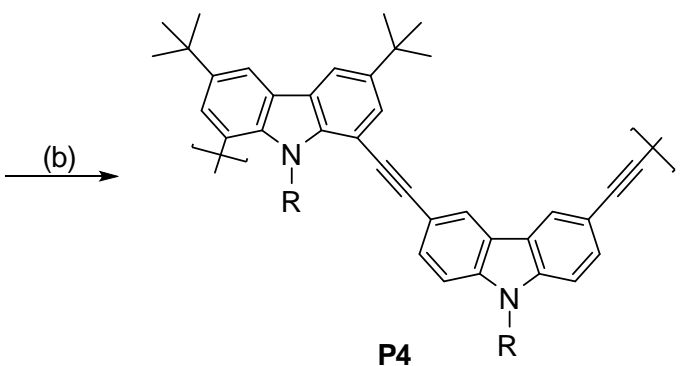

(b)

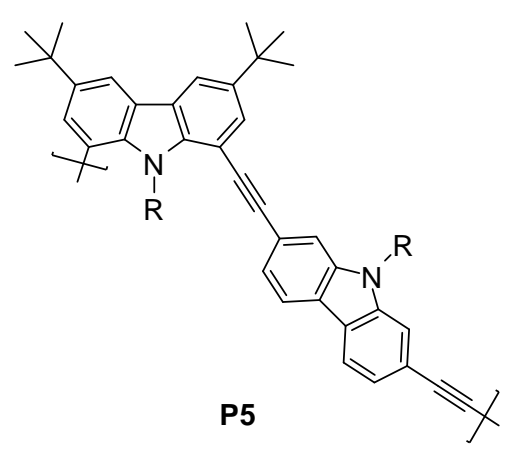


Figure 2. (a) ${ }^{1} \mathrm{H}$ NMR spectrum of $\mathbf{P 4}$ in $\mathrm{C}_{6} \mathrm{D}_{6}$ and (b) IR spectrum of $\mathbf{P 4}(\mathrm{KBr})$.
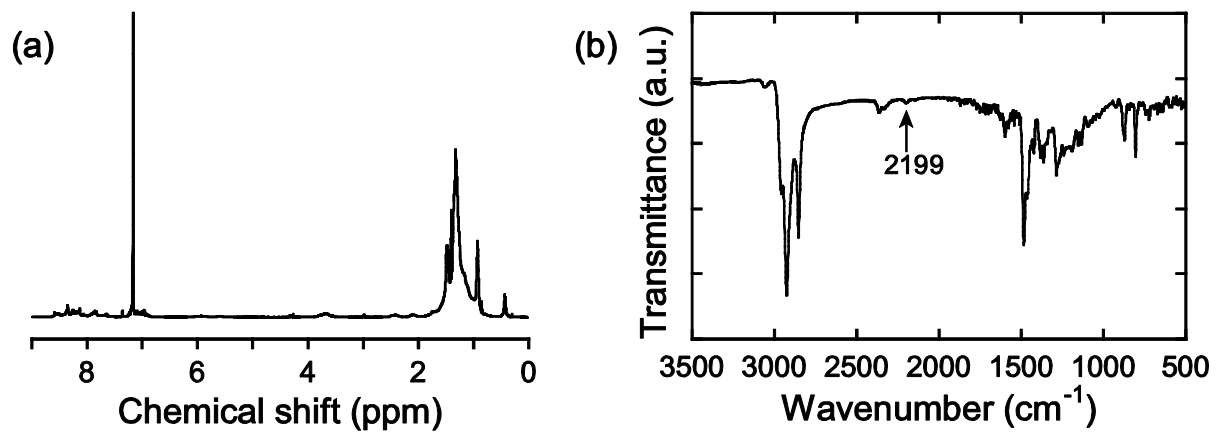

\subsection{Thermal Properties}

Thermogravimetric analysis (TGA) and differential scanning calorimetry (DSC) measurements were performed to estimate the decomposition temperatures and glass transition temperatures $\left(T_{\mathrm{g}}\right)$. Both analyses and measurements were conducted at the scanning rate of $10{ }^{\circ} \mathrm{C} \mathrm{min}{ }^{-1}$ under flowing nitrogen, and the data are summarized in Table 1 . The directly-linked carbazole polymer $\mathbf{P 1}$ started to decompose at $c a .250{ }^{\circ} \mathrm{C}$, and after the stepwise decomposition, the residual soot amount was $c a .10 \%$ at $500{ }^{\circ} \mathrm{C}$ (Figure 3). The incorporation of different $\pi$-chromophores, such as fluorene and bithiophene derivatives, improved the thermal stability. Thus, the decomposition temperatures $\left(T_{5 \%}\right)$ of $\mathbf{P 2}$ and $\mathbf{P 3}$ were higher by $17{ }^{\circ} \mathrm{C}$ than that of $\mathbf{P 1}$. The decomposition temperature increased when alkyne groups were introduced in the polymer main chain. The $T_{5 \%}$ of $\mathbf{P 4}$ was much higher $\left(340{ }^{\circ} \mathrm{C}\right)$ than that of $\mathbf{P 1}$. The thermal stability of $\mathbf{P 5}$ showed a similar improvement due to the presence of the alkyne groups. The different decomposition temperatures between P4 and P5 are consistent with the previous result that the 2,7-carbazolylene unit generally shows a higher thermal stability than the 3,6-carbazolylene unit [27]. It is postulated that these decomposition processes include thermally induced rearrangements of the alkyne moieties. The DSC curves of P1 and P2 did not show well-defined transition temperatures, while P3-P5 displayed $T_{\mathrm{g}} \mathrm{s}$ in the range from 63 to $80{ }^{\circ} \mathrm{C}$.

Figure 3. Thermogravimetric analysis (TGA) curves of P1-P5 at a heating rate of $10{ }^{\circ} \mathrm{C} \min ^{-1}$ under flowing nitrogen.

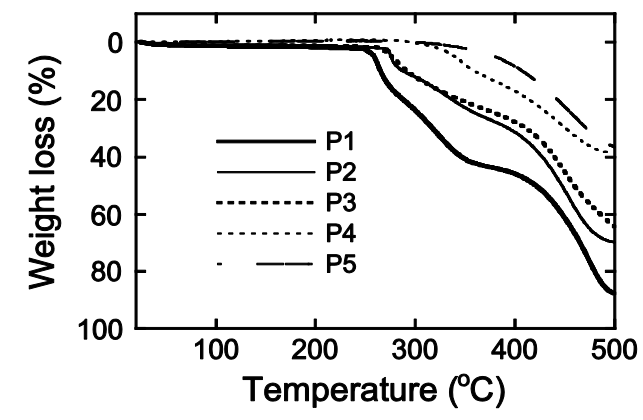

\subsection{Electrochemistry}

Cyclic voltammograms (CVs) of all the polymers were measured both in solutions and in the solid film states. Figure 4 shows the $\mathrm{CV}$ curves of $\mathbf{P 1}-\mathbf{P 5}$ measured in $\mathrm{CH}_{2} \mathrm{Cl}_{2}$ with $0.1 \mathrm{M}\left(n \mathrm{C}_{4} \mathrm{H}_{9}\right)_{4} \mathrm{NClO}_{4}$ at $20{ }^{\circ} \mathrm{C}$, and the oxidation potentials are summarized in Table 2. 
Figure 4. Cyclic voltammograms of (a) P1, (b) P2, (c) P3, (d) P4, and (e) $\mathbf{P 5}$ in $\mathrm{CH}_{2} \mathrm{Cl}_{2}$ with $0.1 \mathrm{M}\left(n \mathrm{C}_{4} \mathrm{H}_{9}\right)_{4} \mathrm{NClO}_{4}$ at the scanning rate of $0.1 \mathrm{~V} \mathrm{~s}^{-1}$ under flowing nitrogen. Potentials vs. $\mathrm{Fc} / \mathrm{Fc}^{+}$couple.
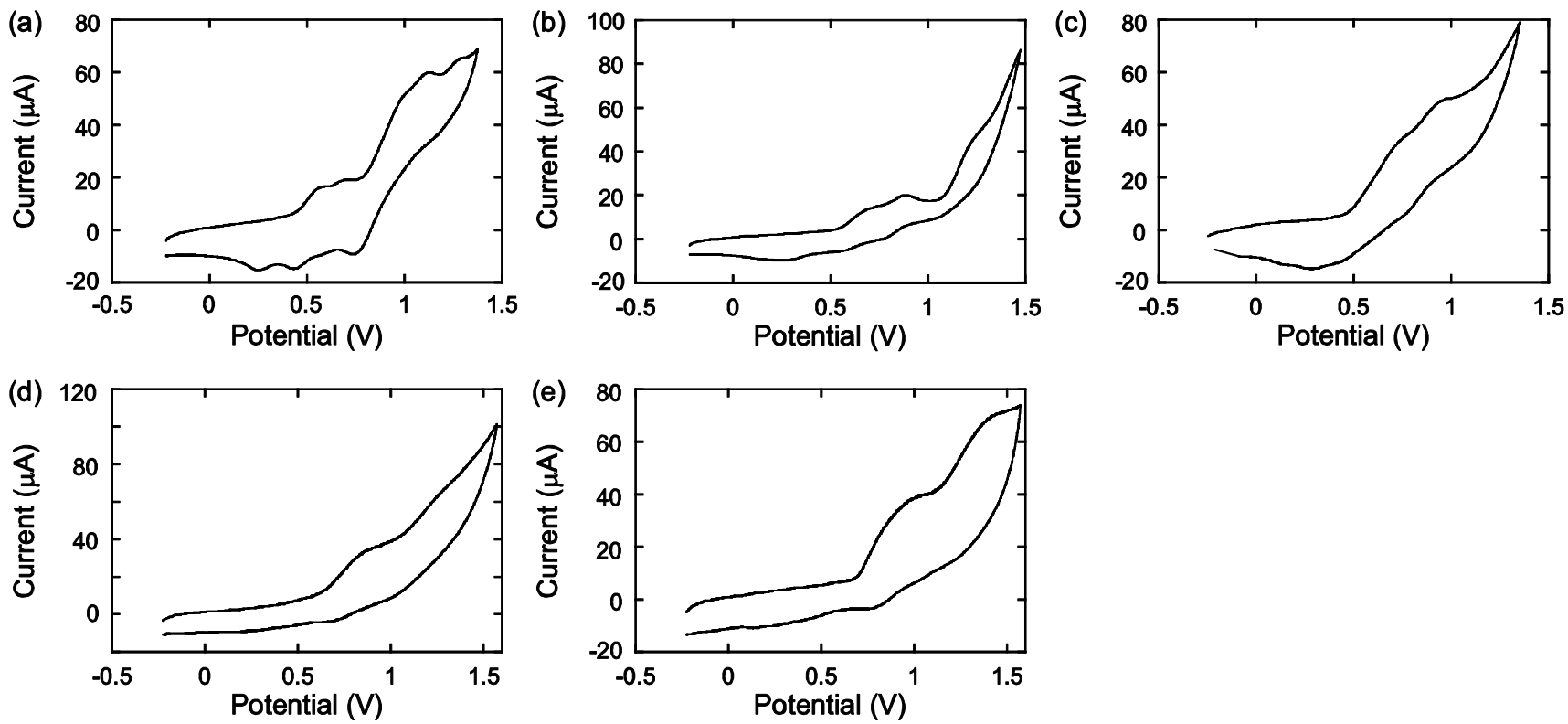

Table 2. Summary of the electrochemistry data of poly(1,8-carbazole $) \mathrm{s}^{\mathrm{a}}$.

\begin{tabular}{|c|c|c|c|c|c|c|}
\hline \multirow[b]{2}{*}{ polymer } & \multicolumn{4}{|c|}{ in $\mathrm{CH}_{2} \mathrm{Cl}_{2}{ }^{\mathrm{b}}$} & \multicolumn{2}{|c|}{ Film $^{c}$} \\
\hline & $E_{\text {onset }}(\mathbf{V})$ & $E^{\circ}(\mathbf{V})^{d}$ & $E_{\mathrm{pa}}(\mathrm{V})^{\mathrm{d}}$ & $E_{\mathrm{pc}}(\mathrm{V})^{\mathrm{d}}$ & $E_{\text {onset }}(\mathbf{V})$ & $E_{\mathrm{pa}}(\mathrm{V})$ \\
\hline \multirow[t]{5}{*}{ P1 } & 0.44 & 0.41 & 0.57 & 0.25 & 0.60 & 0.65 \\
\hline & & 0.58 & 0.70 & 0.45 & & 0.83 \\
\hline & & 0.87 & 0.98 & 0.76 & & 0.92 \\
\hline & & & 1.12 & & & 1.31 \\
\hline & & & 1.28 & & & \\
\hline \multirow[t]{3}{*}{$\mathbf{P} 2$} & 0.55 & 0.48 & 0.67 & 0.29 & 0.66 & 0.71 \\
\hline & & 0.73 & 0.88 & 0.58 & & 1.03 \\
\hline & & & 1.22 & & & 1.27 \\
\hline \multirow[t]{2}{*}{ P3 } & 0.48 & 0.51 & 0.73 & 0.30 & 0.75 & 1.11 \\
\hline & & 0.86 & 0.94 & 0.78 & & \\
\hline \multirow[t]{2}{*}{ P4 } & 0.60 & 0.77 & 0.86 & 0.67 & 0.55 & 0.68 \\
\hline & & 1.15 & 1.25 & 1.05 & & 0.91 \\
\hline \multirow[t]{2}{*}{ P5 } & 0.69 & 0.90 & 1.03 & 0.76 & 0.70 & 0.80 \\
\hline & & & 1.41 & & & 0.97 \\
\hline
\end{tabular}

a Potentials $v s . \mathrm{Fc} / \mathrm{Fc}^{+}$couple. Working electrode: glassy carbon electrode; counter electrode: $\mathrm{Pt}$ wire; reference electrode: $\mathrm{Ag} / \mathrm{Ag}^{+}$.

b Measured in $\mathrm{CH}_{2} \mathrm{Cl}_{2}$ with $0.1 \mathrm{M}\left(n \mathrm{C}_{4} \mathrm{H}_{9}\right)_{4} \mathrm{NClO}_{4}$ at a scanning rate of $0.1 \mathrm{~V} \mathrm{~s}^{-1}$ under flowing nitrogen.

c Measured in $\mathrm{CH}_{3} \mathrm{CN}$ with $0.1 \mathrm{M}\left(n \mathrm{C}_{4} \mathrm{H}_{9}\right)_{4} \mathrm{NClO}_{4}$ at a scanning rate of $0.1 \mathrm{~V} \mathrm{~s}^{-1}$ under flowing nitrogen.

d $E^{\circ}=\left(E_{\mathrm{pc}}+E_{\mathrm{pa}}\right) / 2$, where $E_{\mathrm{pc}}$ and $E_{\mathrm{pa}}$ correspond to the cathodic and anodic peak potentials, respectively. 
Carbazole polymers are redox active polymers in the anodic direction. The first oxidation potentials of all the polymers were almost reversible on the CV time scale. All polymers showed multiple oxidation peaks ascribed to the 1,8-carbazolylene and comonomer moieties. The first oxidations are presumably derived from the carbazole moieties. The first oxidation potentials of P1-P3 were lower than those of P4 and P5. It is postulated that direct substitution of the carbazole 1,8-positions by electron-donating groups, such as carbazole and bithiophene units, lowered the oxidation potential of the 1,8-carbazolylene unit. In contrast, this activation effect by electron-donating substituents is weak in the case of P4 and P5 due to the alkyne spacers. The higher oxidation potential of P5 than that of P4 is consistent with a previous report that poly(2,7-carbazole) derivatives possess deeper HOMO levels than the poly(3,6-carbazole) derivatives [28].

To study the redox activities of P1-P5 in the solid state, the polymer cast films were prepared on a glassy carbon working electrode and subjected to measurements in $\mathrm{CH}_{3} \mathrm{CN}$ with $0.1 \mathrm{M}\left(n \mathrm{C}_{4} \mathrm{H}_{9}\right)_{4} \mathrm{NClO}_{4}$. All the polymer films were insoluble in the electrolyte solution and displayed irreversible oxidation waves. The first oxidation peak potentials of P1-P3 shifted anodically compared to those in the solutions, while P4 and P5 exhibited lower first oxidation peaks or onset potentials than in the solutions. This result suggests different packing modes of the solid states between the directly-linked poly(1,8-carbazole) derivatives and the alkyne-linked poly(1,8-carbazole) derivatives. The coplanarity of the former derivatives would decrease due to the twisted linkage of the $\pi$-chromophores, while the free rotation of the alkyne spacers was supposed to facilitate relatively planar packings of the latter derivatives, leading to a decrease in the oxidation potentials in the solid state.

\section{4. $U V$-vis and Fluorescence Spectroscopies}

The UV-vis absorption and fluorescence spectra of $\mathbf{P 1 - P 5}$ were measured both in $\mathrm{CH}_{2} \mathrm{Cl}_{2}$ and in thin film state (Figure 5). The spectroscopic data are summarized in Table 3.

The longest wavelength absorption maximum $\left(\lambda_{\max }\right)$ of $\mathbf{P 1}$ was detected at $362 \mathrm{~nm}$ in $\mathrm{CH}_{2} \mathrm{Cl}_{2} . \mathbf{P 2}$ and P3 with a linearly conjugated spacer of the fluorene or bithiophene unit showed a slight bathochromic shift in $\lambda_{\max }(366 \mathrm{~nm})$. This bathochromic shift was more significant when the most intense emission peak maxima $\left(\lambda_{\mathrm{em}}\right)$ were noted. The $\lambda_{\mathrm{em}}$ of $\mathbf{P 1}$ was observed at $392 \mathrm{~nm}$, and the value shifted to $412 \mathrm{~nm}$ for $\mathbf{P 2}$ and $467 \mathrm{~nm}$ for P3. Accordingly, the Stokes shift calculated from the $\lambda_{\max }$ and $\lambda_{\mathrm{em}}$ values increased in the order of $\mathbf{P 1}<\mathbf{P 2}<\mathbf{P 3}$. There was a tendency that the quantum yields $\left(\Phi_{\mathrm{f}, \mathrm{sol}}\right)$ in $\mathrm{CH}_{2} \mathrm{Cl}_{2}$ increased with the decreasing Stokes shift values.

It was previously demonstrated that an alkyne group is a superior spacer to expand the effective conjugation length of conjugated carbazole polymers [23,27]. Based on these reports, P4 and P5 displayed the $\lambda_{\max }$ at 378 and $408 \mathrm{~nm}$, respectively. It is also interesting to compare the different connectivity modes of the carbazole unit. The $\lambda_{\max }$ of poly[(3,6-di-tert-butyl- $N$-hexadecyl-1,8carbazolylene)ethynylene] P7 $\left(M_{\mathrm{w}}=9,400, M_{\mathrm{n}}=4,100\right)$ was reported to be $389 \mathrm{~nm}$, which is intermediate between these values (Figure 6) [27]. Although the molecular weight of P5 is slightly larger than those of P4 and P7, the data suggested that the order of the effective conjugation length of the alkyne-linked poly(1,8-carbazole)s is $\mathbf{P 4}<\mathbf{P 7}<\mathbf{P 5}$. In other words, the most efficient $\pi$-spacer is the 2,7-carbazolylene unit, followed by the 1,8-carbazolylene and 3,6-carbazolylene units. A similar tendency was observed for the fluorescence spectra. Both P4 and P5 exhibited two emission maxima 
in $\mathrm{CH}_{2} \mathrm{Cl}_{2}$. The higher energy emission peaks originated from single polymers, while the lower energy emission peaks were presumably derived from the excimers. In the thin film states, the single polymer-based emission completely disappeared and a broad low energy emission was detected at $616 \mathrm{~nm}$ for $\mathbf{P 4}$ and $569 \mathrm{~nm}$ for P5, suggesting the excimer formation.

Figure 5. Normalized UV-vis absorption in $\mathrm{CH}_{2} \mathrm{Cl}_{2}$ measured at $10^{-6} \mathrm{M}$ repeat unit ${ }^{-1}$ (a) and in film (c) and fluorescence spectra in $\mathrm{CH}_{2} \mathrm{Cl}_{2}$ measured at $10^{-6} \mathrm{M}$ repeat unit $^{-1}$ (b) and in film (d) of P1-P5.

(a)

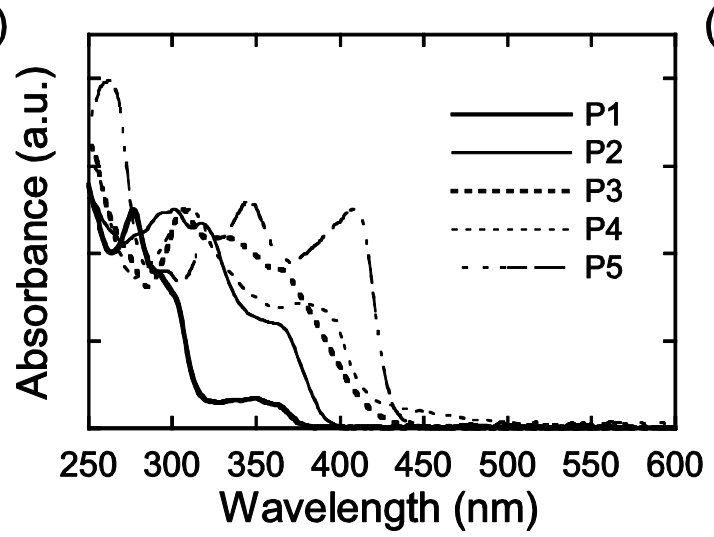

(c)

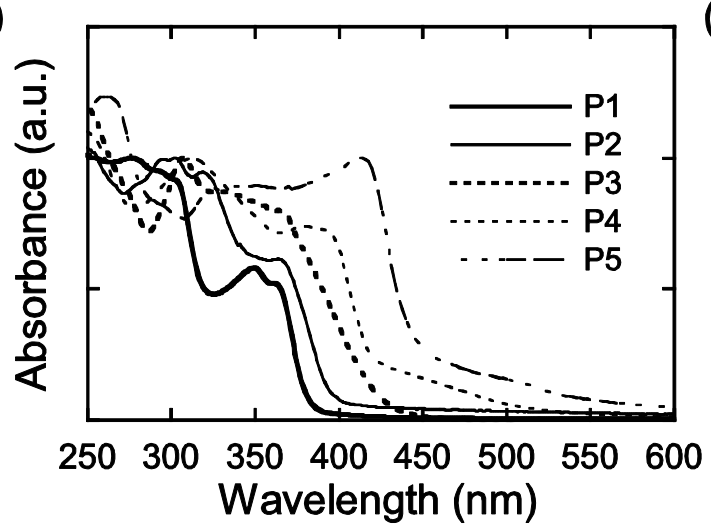

(b)

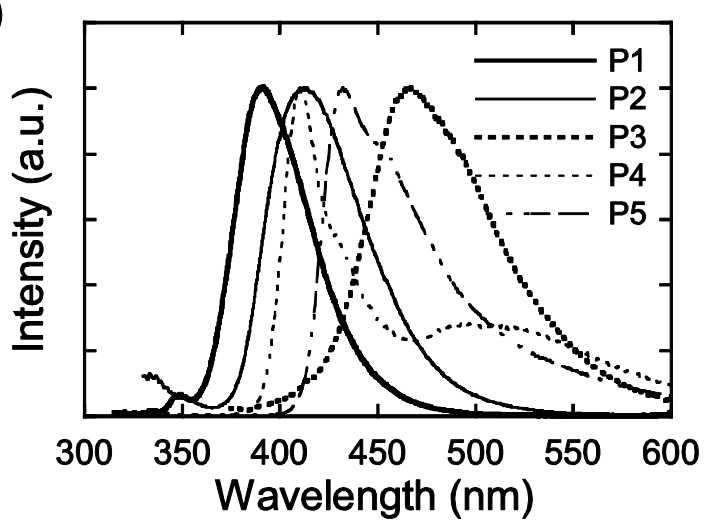

(d)

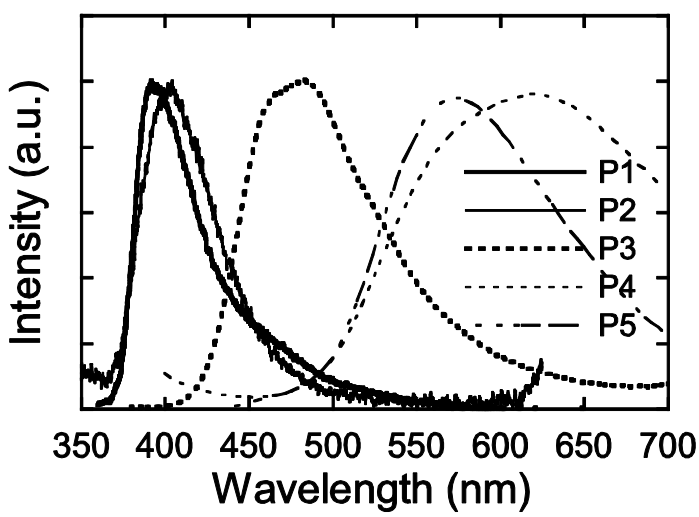

Table 3. Summary of the optical properties of poly(1,8-carbazole)s.

\begin{tabular}{|c|c|c|c|c|c|c|}
\hline \multirow[b]{2}{*}{ polymer } & \multicolumn{4}{|c|}{ in $\mathrm{CH}_{2} \mathrm{Cl}_{2}$} & \multicolumn{2}{|c|}{ Film } \\
\hline & $\begin{array}{l}\lambda_{\max } \\
(\mathbf{n m})\end{array}$ & $\begin{array}{c}\lambda_{\mathrm{em}}(\mathbf{n m}) \\
{\left[\lambda_{\mathrm{ex}}(\mathbf{n m})\right]}\end{array}$ & $\begin{array}{c}\text { Stokes shift } \\
\left(\mathrm{cm}^{-1}\right)\end{array}$ & $\Phi_{\mathrm{f}, \mathrm{sol}}{ }^{\mathrm{a}}$ & $\begin{array}{l}\lambda_{\max } \\
(\mathrm{nm})\end{array}$ & $\begin{array}{c}\lambda_{\mathrm{em}}(\mathbf{n m}) \\
{\left[\lambda_{\mathrm{ex}}(\mathbf{n m})\right]}\end{array}$ \\
\hline P1 & 362 & 392 [302] & 2114 & 0.250 & 362 & $392[350]$ \\
\hline $\mathbf{P 2}$ & 366 & 412 [317] & 3050 & 0.419 & 364 & 404 [319] \\
\hline P3 & 366 & 467 [366] & 5909 & 0.125 & 366 & 486 [366] \\
\hline P4 & 378 & $410,497[315]$ & 2065 & 0.352 & 380 & 616 [380] \\
\hline P5 & 408 & $432,457^{\mathrm{b}}[348]$ & 1362 & 0.496 & 414 & 569 [414] \\
\hline
\end{tabular}

a Determined against quinine sulfate in $0.05 \mathrm{M}$ aqueous $\mathrm{H}_{2} \mathrm{SO}_{4}\left(\Phi_{\mathrm{f}}=0.546\right)$ as a standard.

b Shoulder. 
Figure 6. Chemical structure of P6 and P7.

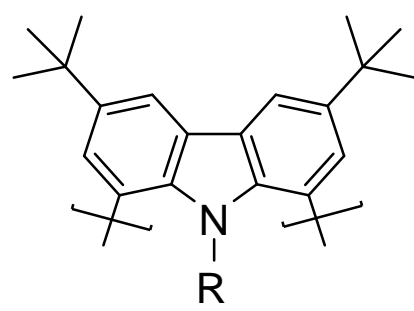

P6

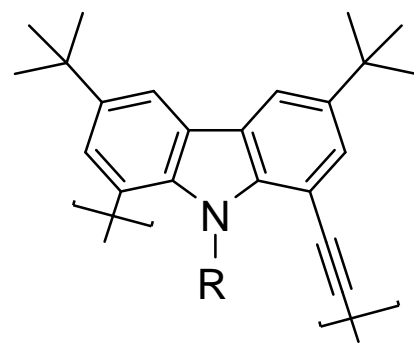

P7

The energy diagrams of P1-P5 were determined from the electrochemistry data and UV-vis absorption spectra (Figure 7). The HOMO levels were calculated from the $E_{\text {onset }}$ values of the solution $\mathrm{CVs}$ based on the assumption of $\mathrm{Fc} / \mathrm{Fc}^{+}=-4.80 \mathrm{eV}$. The LUMO levels were estimated from the HOMO levels and the optical band gaps in $\mathrm{CH}_{2} \mathrm{Cl}_{2}$. The diagrams revealed that the HOMO levels of P1-P5 are similar at $-5.37 \pm 0.12 \mathrm{eV}$, while the LUMO levels are quite dependent on the comonomer or spacer structures. In particular, the presence of alkyne spacers led to a considerable lowering of the polymer LUMO levels. To obtain further insight into the chemical structure-energy level relationship, the effects of the different connectivities of the carbazole units was considered. The HOMO and LUMO levels of poly(3,6-di-tert-butyl- $N$-hexadecyl-1,8-carbazolylene) P6 were reported to be -5.56 and $-2.27 \mathrm{eV}$, respectively [27]. A comparison of this energy level to that of P1 suggested that the copolymerization of $\mathbf{1}$ with the 3,6-carbazolylene unit $\mathbf{2}$ results in an elevation of both the HOMO and LUMO levels. A higher HOMO level generally facilitates oxidation or p-type doping. Judging from the estimated energy levels, it is thus expected that $\mathbf{P 1}$ is a better p-type semiconductor than P6. The energy levels of P4, P5, and P7 were similarly compared. The HOMO and LUMO levels of P7 were reported to be -5.05 and $-2.58 \mathrm{eV}$, respectively [27]. Replacement of half of the 1,8-carbazolylene units of P7 by the 3,6-carbazolylene or 2,7-carbazolylene units resulted in an elevation of the HOMO level and a lowering of the LUMO level, namely decreased band gaps. The extent of the lowered LUMO level is more significant for P4 than for P5. A comparison between P1 and P4 also suggested that the insertion of one alkyne spacer into the polymer repeat unit lowers the LUMO level by ca. $1.3 \mathrm{eV}$.

Figure 7. Schematic energy level diagrams of P1-P5.

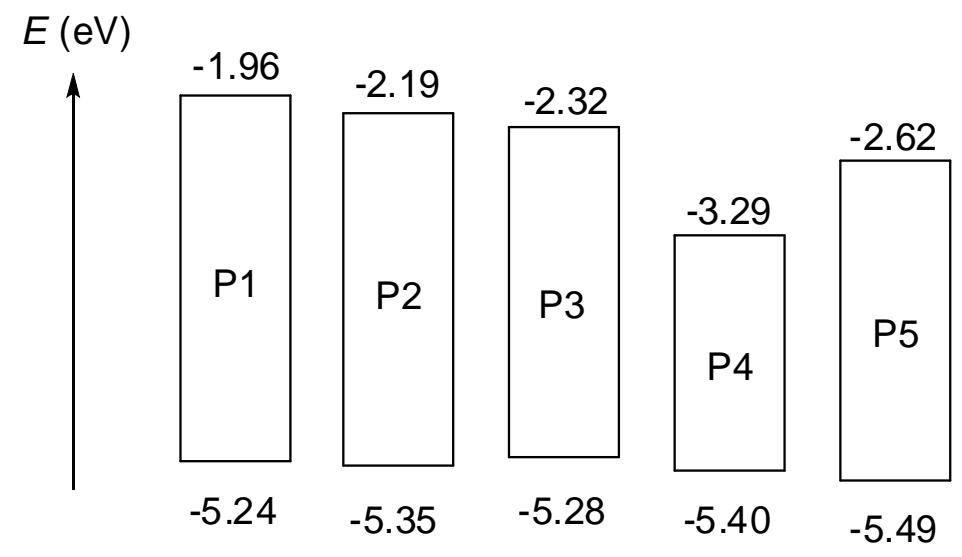


Although P1-P5 did not exhibit solvatochromic behaviors in homogeneous solutions, solvent effects on the optical properties were further pursued. The addition of methanol to the homogeneous polymer solution is a general method to investigate the aggregation behaviors [29,30]. The emission spectra of the alkyne-linked polymers P4 and P5 were completely different between the solutions and the solid films. Therefore, the UV-vis absorption and fluorescence spectra of these polymers were measured as a function of the methanol content. The addition of methanol to the homogeneous polymer solutions in $\mathrm{CH}_{2} \mathrm{Cl}_{2}$ led to a gradual bathochromic shift in the absorption spectra (Figures 8a and $8 \mathrm{c}$ ). This behavior became more significant in the fluorescence spectra. The initial single polymer-based emission peak started to decrease and a new low energy peak ascribed to an excimer formation appeared when more methanol was added (Figures $8 \mathrm{~b}$ and 8d). The extent of this aggregation behavior is more remarkable for $\mathbf{P 5}$ than for $\mathbf{P 4}$, presumably reflecting the ready intermolecular packing due to the relatively linear 2,7-carbazolylene unit. Note that the zigzagged conformation of the conjugated carbazole polymers is suitable for aggregation suppression and, accordingly, stable blue light emission in the solid state [27,31]. Therefore, P4 composed of the 1,8-carbazolylene and 3,6-carbazolylene units possessed a feature of aggregation suppression similar to P7. However, the excimer formation could not be perfectly inhibited in the $\mathrm{CH}_{2} \mathrm{Cl}_{2}: \mathrm{MeOH}$ mixtures.

Figure 8. Solvatochromic behaviors of UV-vis absorption (a, P4; c, P5) and fluorescence spectra (b, P4; d, P5) in $\mathrm{CH}_{2} \mathrm{Cl}_{2} / \mathrm{MeOH}$ mixtures.

(a)

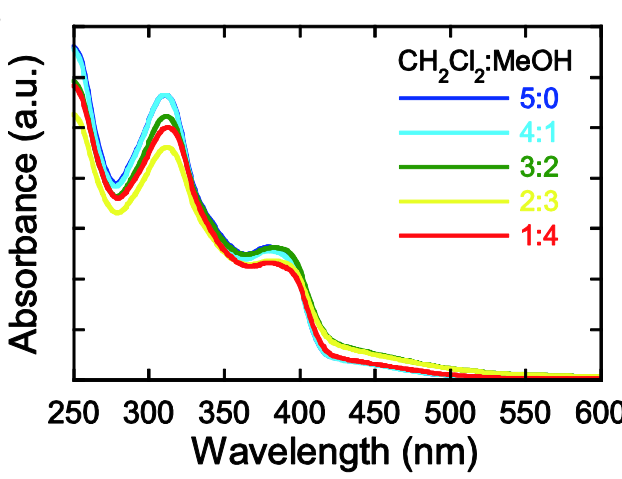

(c)

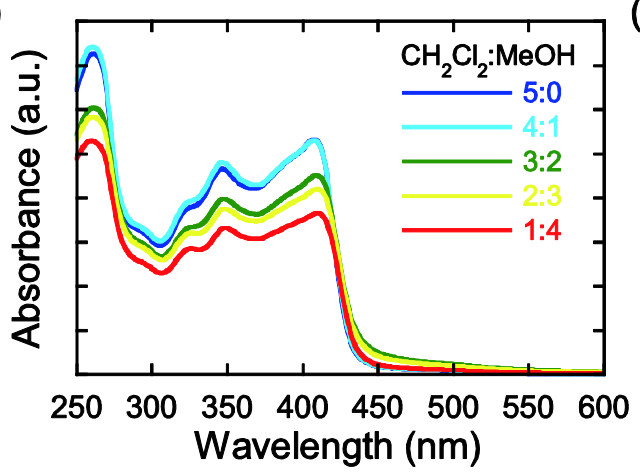

(b)

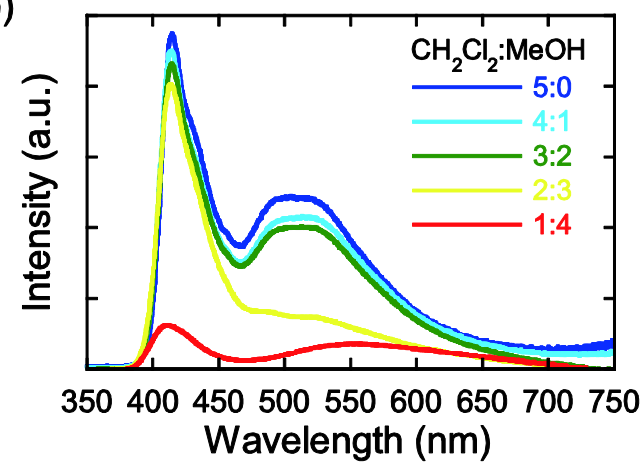

(d)

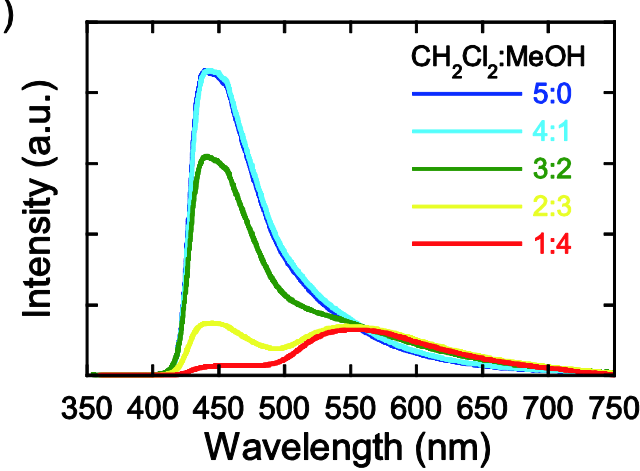

\section{Experimental Section}

\subsection{Materials}

All reagents including 2,2'-(9,9-dihexyl-9H-fluorene-2,7-diyl)bis(1,3,2-dioxaborinane) (3) and 2,2'-(2,2'-bithiene-5,5'-diyl)bis(4,4,5,5-tetramethyl-1,3,2-dioxaborolane) (4) were purchased from 
Kanto, Tokyo Kasei, and Wako and used as received. 3,6-Di-tert-butyl-9-hexadecyl-1,8-diiodo-9Hcarbazole (1) [25], 3,6-diethynyl-9-hexadecyl-9H-carbazole (5) [32], and 2,7-diethynyl-9-hexadecyl$9 H$-carbazole (6) [33] were prepared according to the literature methods.

\subsection{Measurements}

${ }^{1} \mathrm{H}$ NMR and ${ }^{13} \mathrm{C}$ NMR spectra were measured on a JEOL model AL400 spectrometer at $20{ }^{\circ} \mathrm{C}$. Chemical shifts are reported in ppm downfield from $\mathrm{SiMe}_{4}$, using the solvent's residual signal as an internal reference. Coupling constants $(J)$ are given in Hertz. The resonance multiplicity is described as $\mathrm{s}$ (singlet), $\mathrm{d}$ (doublet), $\mathrm{t}$ (triplet), and $\mathrm{m}$ (multiplet). Infrared (IR) spectra were recorded on a JASCO FT/IR-4100 spectrometer. MALDI-TOF MS spectra were measured on an Applied Biosystems model Voyager-DE STR in reflector mode. UV-vis spectra were recorded on a JASCO V-550 spectrophotometer. The solution spectra were measured in a quartz cuvette of $1 \mathrm{~cm}$. Fluorescence spectra were measured on a JASCO FP6500 spectrophotometer. Quantum yields were determined against quinine sulfate in $0.05 \mathrm{M}$ aqueous $\mathrm{H}_{2} \mathrm{SO}_{4}\left(\Phi_{\mathrm{F}}=0.546\right)$ [34]. Gel permeation chromatography (GPC) was measured on a JASCO system equipped with polystyrene gel columns using THF as an

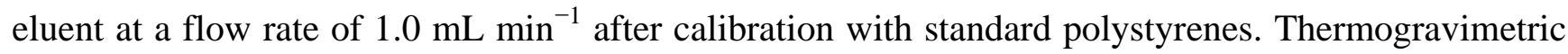
analysis (TGA) and differential scanning calorimetry (DSC) measurement were carried out on a Rigaku Thermoplus TG8120 and DSC8230, respectively, under flowing nitrogen at a scanning rate of $10{ }^{\circ} \mathrm{C} \mathrm{min}{ }^{-1}$. Electrochemistry measurements were carried out at $20{ }^{\circ} \mathrm{C}$ in a classical three-electrode cell. The working, reference, and auxiliary electrodes were a glassy carbon disk electrode $\left(0.07 \mathrm{~cm}^{2}\right)$, $\mathrm{Ag} / \mathrm{Ag}^{+} / \mathrm{CH}_{3} \mathrm{CN} /\left(n \mathrm{C}_{4} \mathrm{H}_{9}\right)_{4} \mathrm{NClO}_{4}$, and Pt wire, respectively.

9-Hexadecyl-3,6-bis(4,4,5,5-tetramethyl-1,3,2-dioxaborolan-2-yl)-9H-carbazole (2). To a solution of 3,6-dibromo-9-hexadecyl-9H-carbazole [25] (3.00 g, $5.46 \mathrm{mmol})$ in THF (50 $\mathrm{mL})$ at $-78{ }^{\circ} \mathrm{C}, 1.6 \mathrm{M} n$-butyllithium in hexane $(7.8 \mathrm{~mL})$ was added dropwise. After the solution was stirred for $20 \mathrm{~min}$, isopropoxy-4,4,5,5-tetramethyl-1,3,2-dioxaborolane (2.33 g, $12.5 \mathrm{mmol})$ was added. The mixture was stirred at $-78{ }^{\circ} \mathrm{C}$ for $5 \mathrm{~min}$, warmed to $20{ }^{\circ} \mathrm{C}$, and stirred for $12 \mathrm{~h}$. After the solution was poured into an ice-water mixture, the organic phase was extracted with $\mathrm{CH}_{2} \mathrm{Cl}_{2}$ and washed with brine. Evaporation and column chromatography $\left(\mathrm{SiO}_{2}\right.$, hexane/EtOAc $\left.=10: 1\right)$ afforded the desired compound $2(1.44 \mathrm{~g}, 41 \%) .{ }^{1} \mathrm{H}$ NMR $\left(400 \mathrm{MHz}, \mathrm{CDCl}_{3}\right): \delta 0.88(\mathrm{t}, J=6 \mathrm{~Hz}, 3 \mathrm{H}), 1.22(\mathrm{~s}, 6 \mathrm{H})$, $1.25(\mathrm{~s}, 6 \mathrm{H}), 1.40(\mathrm{~s}, 26 \mathrm{H}), 1.85(\mathrm{t}, J=6 \mathrm{~Hz}, 2 \mathrm{H}), 4.30(\mathrm{t}, J=6 \mathrm{~Hz}, 2 \mathrm{H}), 7.38(\mathrm{~d}, J=8 \mathrm{~Hz}, 2 \mathrm{H})$, $7.90(\mathrm{~d}, J=8 \mathrm{~Hz}, 2 \mathrm{H}), 8.66(\mathrm{~s}, 2 \mathrm{H}) .{ }^{13} \mathrm{C} \mathrm{NMR}\left(100 \mathrm{MHz}, \mathrm{CDCl}_{3}\right): \delta 14.11,22.68,24.93,27.22$, 28.90, 29.35, 29.38, 29.46, 29.56, 29.57, 29.61, 29.65, 29.68, 31.91, 43.12, 83.50, 108.10, 122.80, 128.05, 131.95, 142.65. IR (KBr): 3046, 2978, 2922, 2851, 1628, 1598, 1574, 1469, 1351, 1271, 1255, 1215, 1145, 1083, 1054, 1027, 963, 903, 894, 860, 810, 749, 720, 702, 674, 638, 580, $420 \mathrm{~cm}^{-1}$. MALDI-TOF MS [2-(4-hydroxyphenylazo)benzoic acid]: $\mathrm{m} / \mathrm{z}$ : calculated for $\mathrm{C}_{40} \mathrm{H}_{63} \mathrm{~B}_{2} \mathrm{NO}_{4}{ }^{+}$: $643.49 \mathrm{~g} \mathrm{~mol}^{-1}$; found: $643.71 \mathrm{~g} \mathrm{~mol}^{-1}\left[\mathrm{M}^{+}\right]$.

P1. To a $100 \mathrm{~mL}$ Schlenk tube, 1 (121 mg, $0.160 \mathrm{mmol}), 2$ (103 mg, $0.160 \mathrm{mmol})$, dehydrated THF $(1.3 \mathrm{~mL})$, and $2 \mathrm{M}$ aq. $\mathrm{K}_{2} \mathrm{CO}_{3}(0.315 \mathrm{~mL})$ were added. Under nitrogen atmosphere, a catalytic amount of $\mathrm{Pd}\left(\mathrm{PPh}_{3}\right)_{4}$ was added, and the mixture was refluxed for $72 \mathrm{~h}$. After cooling to $20{ }^{\circ} \mathrm{C}$, the reaction mixture was diluted with $\mathrm{CH}_{2} \mathrm{Cl}_{2}$ and the organic phase was washed with water and dried over $\mathrm{Na}_{2} \mathrm{SO}_{4}$. Evaporation of the solvents and precipitation into $\mathrm{CH}_{3} \mathrm{OH}$ afforded the desired polymer. The 
precipitate was filtered and dried in vacuo $(40.3 \mathrm{mg}, 28 \%) .{ }^{1} \mathrm{H}$ NMR (400 MHz, $\left.\mathrm{C}_{6} \mathrm{D}_{6}\right): \delta 0.90-1.16(\mathrm{~m}$, 80n H), 3.57-3.87 (m, 4n H), 7.19-7.22 (m, 4n H), 7.66-7.75 (m, 2n H), 8.13-8.61 (m, 4n H). IR (KBr): 2953, 2923, 2851, 1599, 1479, 1467, 1351, 1329, 1260, 1213, 1145, 1083, 1048, 1024, 964, $867,809 \mathrm{~cm}^{-1}$.

P2. To a $100 \mathrm{~mL}$ Schlenk tube, 1 (130 mg, $0.171 \mathrm{mmol}), 3$ (86.1 mg, $0.171 \mathrm{mmol})$, dehydrated THF $(2.0 \mathrm{~mL})$, and $2 \mathrm{M}$ aq. $\mathrm{K}_{2} \mathrm{CO}_{3}(0.335 \mathrm{~mL})$ were added. Under nitrogen atmosphere, a catalytic amount of $\mathrm{Pd}\left(\mathrm{PPh}_{3}\right)_{4}$ was added, and the mixture was refluxed for $72 \mathrm{~h}$. After cooling to $20{ }^{\circ} \mathrm{C}$, the reaction mixture was diluted with $\mathrm{CH}_{2} \mathrm{Cl}_{2}$ and the organic phase was washed with water and dried over $\mathrm{Na}_{2} \mathrm{SO}_{4}$. Evaporation of the solvents and precipitation into $\mathrm{CH}_{3} \mathrm{OH}$ afforded the desired polymer. The precipitate was filtered and dried in vacuo $(94.7 \mathrm{mg}, 61 \%) .{ }^{1} \mathrm{H} \mathrm{NMR}\left(400 \mathrm{MHz}, \mathrm{C}_{6} \mathrm{D}_{6}\right): \delta 0.80-1.67$ (m, 75n H), 3.64-3.65 (m, 2n H), 7.72-8.50 (m, 10n H). IR (KBr): 3054, 2954, 2923, 2852, 1608, 1567, 1540, 1481, 1465, 1434, 1412, 1362, 1311, 1275, 1245, 1183, 1123, 1096, 1049, 869, 825, 805, 750, $721,694 \mathrm{~cm}^{-1}$.

P3. To a $20 \mathrm{~mL}$ round-bottle flask, 1 (165 mg, $0.214 \mathrm{mmol}), 4(89.9 \mathrm{mg}, 0.214 \mathrm{mmol})$, dehydrated THF (2.0 mL), and $2 \mathrm{M}$ aq. $\mathrm{K}_{2} \mathrm{CO}_{3}(0.425 \mathrm{~mL})$ were added. Under nitrogen atmosphere, a catalytic amount of $\mathrm{Pd}\left(\mathrm{PPh}_{3}\right)_{4}$ was added, and the mixture was refluxed for $72 \mathrm{~h}$. After cooling to $20{ }^{\circ} \mathrm{C}$, the reaction mixture was diluted with $\mathrm{CH}_{2} \mathrm{Cl}_{2}$ and the organic phase was washed with water and dried over $\mathrm{Na}_{2} \mathrm{SO}_{4}$. Evaporation of the solvents and precipitation into $\mathrm{CH}_{3} \mathrm{OH}$ afforded the desired polymer. The precipitate was filtered and dried in vacuo $(20.8 \mathrm{mg}, 15 \%) .{ }^{1} \mathrm{H}$ NMR $\left(400 \mathrm{MHz}, \mathrm{C}_{6} \mathrm{D}_{6}\right): \delta 0.90-1.44$ (m, 49n H), 4.20 (br s, 2n H), 6.64-8.41 (m, 8n H). IR (KBr): 3065, 2956, 2922, 2851, 1520, 1480, 1465, 1443, 1416, 1380, 1362, 1335, 1268, 1243, 1201, 1143, 1049, 1002, 871, $800 \mathrm{~cm}^{-1}$.

P4. To a $30 \mathrm{~mL}$ round-bottle flask, 1 (100 mg, $0.133 \mathrm{mmol}), 5(58.8 \mathrm{mg}, 0.133 \mathrm{mmol}), i \operatorname{Pr}_{2} \mathrm{NH}$ $(0.88 \mathrm{~mL})$, and toluene $(2.6 \mathrm{~mL})$ were added. After bubbling $\mathrm{N}_{2}$ gas for $1 \mathrm{~h}, \mathrm{PdCl}_{2}\left(\mathrm{PPh}_{3}\right)_{2}(3.7 \mathrm{mg}$, $0.053 \mathrm{mmol})$ and $\mathrm{CuI}(1.5 \mathrm{mg}, 0.0078 \mathrm{mmol})$ were added and the reaction mixture was heated to $80{ }^{\circ} \mathrm{C}$ for $24 \mathrm{~h}$. After cooling to $20{ }^{\circ} \mathrm{C}$, the solution was diluted with $\mathrm{CH}_{2} \mathrm{Cl}_{2}$ and poured into $\mathrm{CH}_{3} \mathrm{OH}$. The precipitate was collected, and the polymer was purified by reprecipitation into $\mathrm{CH}_{3} \mathrm{OH}$ and then dried in vacuo $(99.5 \mathrm{mg}, 99 \%) .{ }^{1} \mathrm{H}$ NMR (400 MHz, $\left.\mathrm{C}_{6} \mathrm{D}_{6}\right): \delta 0.83-1.48(\mathrm{~m}, 76 \mathrm{n} \mathrm{H})$, 2.10-2.14 (m, 4n H), 3.64-3.69 (m, 4n H), 6.87-8.59 (m, 10n H). IR (KBr): 3055, 2953, 2922, 2851, 2199, 1481, 1382, 1362, 1283, 1149, 1132, 870, $804 \mathrm{~cm}^{-1}$.

P5. To a $30 \mathrm{~mL}$ round-bottle flask, 1 (100 mg, $0.133 \mathrm{mmol}), 6(58.8 \mathrm{mg}, 0.133 \mathrm{mmol}), i \operatorname{Pr}_{2} \mathrm{NH}$ $(0.88 \mathrm{~mL})$, and toluene $(2.7 \mathrm{~mL})$ were added. After bubbling $\mathrm{N}_{2}$ gas for $1 \mathrm{~h}, \mathrm{PdCl}_{2}\left(\mathrm{PPh}_{3}\right)_{2}(3.7 \mathrm{mg}$, $0.053 \mathrm{mmol})$ and $\mathrm{CuI}(1.3 \mathrm{mg}, 0.0068 \mathrm{mmol})$ were added and the reaction mixture was heated to $80{ }^{\circ} \mathrm{C}$ for $24 \mathrm{~h}$. After cooling to $20{ }^{\circ} \mathrm{C}$, the solution was diluted with $\mathrm{CH}_{2} \mathrm{Cl}_{2}$ and poured into $\mathrm{CH}_{3} \mathrm{OH}$. The precipitate was collected, and the polymer was purified by reprecipitation into $\mathrm{CH}_{3} \mathrm{OH}$ and then dried in vacuo $(115 \mathrm{mg}, 100 \%) .{ }^{1} \mathrm{H}$ NMR (400 MHz, $\left.\mathrm{C}_{6} \mathrm{D}_{6}\right): \delta 0.82-1.75(\mathrm{~m}, 76 \mathrm{n} \mathrm{H})$, 2.40 (br s, 4n H), 3.91 (br s, 4n H), 7.00-8.34 (m, 10n H). IR (KBr): 3065, 2953, 2922, 2851, 2196, $1600,1482,1456,1434,1387,1362,1322,1345,1188,871,849,804 \mathrm{~cm}^{-1}$.

\section{Conclusions}

A variety of 1,8-carbazole-based conjugated copolymers was synthesized by the Suzuki or Sonogashira polycondensation between the 1,8-diiodocarbazole derivative and the corresponding 
bifunctional comonomers. The insertion of alkyne spacers was found to increase the molecular weights of the resulting polymers and improve the thermal stability. The polymer energy levels were comprehensively investigated by optical and electrochemical measurements. The data revealed that the polymer LUMO levels are variable using different comonomer or spacer structures, while the HOMO levels are almost constant with a high quality p-type semiconducting feature. This result suggests that the obtained polymers fit the standard anode materials such as ITO with the ionization potential of ca. $5.0 \mathrm{eV}$ as well as the various cathode materials such as $\mathrm{Al}$ with the work function of $c a .3 .5 \mathrm{eV}$. It was also demonstrated that the presence of alkyne spacers expands the effective conjugation length, but it also enhances the aggregation propensity of the copolymers. Further diversification of the comonomer structures will lead to realization of the 1,8-carbazole-based conjugated polymers suitable for specific applications in organic electronic devices.

\section{Acknowledgements}

This work was supported, in part, by a Grant-in-Aid for Scientific Research and Special Coordination Funds for Promoting Science and Technology from MEXT, Japan, the Murata Science Foundation, the Izumi Science and Technology Foundation, and the Yazaki Memorial Foundation for Science and Technology.

\section{References and Notes}

1. Grazulevicius, J.V.; Strohriegl, P.; Pielichowski, J.; Pielichowski, K. Carbazole-containing polymers: Synthesis, properties and applications. Prog. Polym. Sci. 2003, 28, 1297-1353.

2. Wakim, S.; Aïch, B.-R.; Tao, Y.; Leclerc, M. Charge transport, photovoltaic, and thermoelectric properties of poly(2,7-carbazole) and poly(indolo[3,2-b]carbazole) derivatives. Polym. Rev. 2008, $48,432-462$.

3. Tao, X.-T.; Zhang, Y.-D.; Wada, T.; Sasabe, H.; Suzuki, H.; Watanabe, T.; Miyata, S. Hyperbranched polymers for electroluminescence applications. Adv. Mater. 1998, 10, 226-230.

4. Zhang, Z.-B.; Fujiki, M.; Tang, H.-Z.; Motonaga, M. Torimitsu, K. The first high molecular weight poly(n-alkyl-3,6-carbazole)s. Macromolecules 2002, 35, 1988-1990.

5. Zhang, Z.-B.; Motonaga, M.; Fujiki, M.; McKenna, C.E. The first optically active polycarbazoles. Macromolecules 2003, 36, 6956-6958.

6. Liou, G.-S.; Hsiao, S.-H.; Chen, H.-W. Novel high- $T_{\mathrm{g}}$ poly(amine-imide)s bearing pendent N-phenylcarbazole units: synthesis and photophysical, electrochemical and electrochromic properties. J. Mater. Chem. 2006, 16, 1831-1842.

7. Tsuchiya, K.; Sakaguchi, K.; Kasuga, H.; Kawakami, A.; Taka, H.; Kita, H.; Ogino, K. Synthesis of charge transporting block copolymers containing 2,7-dimethoxycarbazole units for light emitting device. Polymer 2010, 51, 616-622.

8. Morin, J.-F.; Leclerc, M. Syntheses of conjugated polymers derived from N-Alkyl-2,7-carbazoles. Macromolecules 2001, 34, 4680-4682.

9. Dierschke, F.; Grimsdale, A.C.; Müllen, K. Efficient synthesis of 2,7-dibromocarbazoles as components for electroactive materials. Synthesis 2003, 16, 2470-2472. 
10. Blouin, N.; Leclerc, M. Poly(2,7-carbazole)s: Structure-property relationships. Acc. Chem. Res. 2008, 41, 1110-1119.

11. Boudreault, P.-L.; Blouin, N.; Leclerc, M. Poly(2,7-carbazole)s and related polymers. Adv. Polym. Sci. 2008, 212, 99-124.

12. Leclerc, N.; Michaud, A.; Sirois, K.; Morin, J.-F.; Leclerc, M. Synthesis of 2,7-carbazolenevinylene-based copolymers and characterization of their photovoltaic properties. Adv. Funct. Mater. 2006, 16, 1694-1704.

13. Blouin, N.; Michaud, A.; Leclerc, M. A low-bandgap poly(2,7-carbazole) derivative for use in high-performance solar cells. Adv. Mater. 2007, 19, 2295-2300.

14. Blouin, N.; Michaud, A.; Gendron, D.; Wakim, S.; Blair, E.; Neagu-Plesu, R.; Belletête, M.; Durocher, G.; Tao, Y.; Leclerc, M. Toward a rational design of poly(2,7-carbazole) derivatives for solar cells. J. Am. Chem. Soc. 2008, 130, 732-742.

15. Zou, Y.; Gendron, D.; Badrou-Aïch, R.; Najari, A.; Tao, Y.; Leclerc, M. A high-mobility low-bandgap poly(2,7-carbazole) derivative for photovoltaic applications. Macromolecules 2009, 42, 2891-2894.

16. Park, S.H.; Roy, A.; Beaupré, S.; Cho, S.; Coates, N.; Moon, J.S.; Moses, D.; Leclerc, M.; Lee, K.; Heeger, A.J. Bulk heterojunction solar cells with internal quantum efficiency approaching $100 \%$. Nat. Photonics 2009, 3, 297-303.

17. Wu, C.-W.; Lin, H.-C. Synthesis and characterization of kinked and hyperbranched carbazole/fluorene-based copolymers. Macromolecules 2006, 39, 7232-7340.

18. Tamura, K.; Shiotsuki, M.; Kobayashi, N.; Masuda, T.; Sanda, F. Synthesis of highly conjugated poly(3,9-carbazolyleneethynylenearylene)s emitting variously colored fluorescence. Polymer 2009, $50,4479-4487$.

19. Tamura, K.; Shiotsuki, M.; Kobayashi, N.; Masuda, T.; Sanda, F. Synthesis and properties of conjugated polymers containing 3,9- and 2,9-linked carbazole units in the main chain. J. Polym. Sci. A 2009, 47, 3509-3517.

20. Sasano, T.; Sogawa, H.; Tamura, K.; Shiotsuki, M.; Masuda, T.; Sanda, F. Synthesis and properties of conjugated polymers containing 3,9-carbazolylene and silylenevinylene moieties in the main chain. J. Polym. Sci. A 2010, 48, 1815-1821.

21. Michinobu, T.; Kumazawa, H.; Shigehara, K. Nitrogen-linked aromatic poly(2,7-carbazole)s: Partially annulated poly ( $m$-aniline)s. Chem. Lett. 2007, 36, 620-621,

22. Michinobu, T.; Okoshi, K.; Osako, H.; Kumazawa, H.; Shigehara, K. Synthesis and optical properties of carbazole-containing donor-acceptor type conjugated polymers. J. Photopolym. Sci. Technol. 2007, 20, 255-256.

23. Michinobu, T.; Okoshi, K.; Osako, H.; Kumazawa, H.; Shigehara, K. Band-gap tuning of carbazole-containing donor-acceptor type conjugated polymers by acceptor moieties and $\pi$-spacer groups. Polymer 2008, 49, 192-199.

24. Michinobu, T.; Kumazawa, H.; Otsuki, E.; Usui, H.; Shigehara, K. Synthesis and properties of nitrogen-linked poly(2,7-carbazole)s as hole-transport material for organic light emitting diodes. $J$. Polym. Sci. A 2009, 47, 3880-3891.

25. Michinobu, T.; Osako, H.; Shigehara, K. Alkyne-linked poly(1,8-carbazole)s: A novel class of conjugated carbazole polymers. Macromol. Rapid Commun. 2008, 29, 111-116. 
26. Michinobu, T.; Osako, H.; Murata, K.; Shigehara, K. Blue, green, and red light emission of 1,8-carbazole-based conjugated polymers. Chem. Lett. 2010, 39, 168-169.

27. Michinobu, T.; Osako, H.; Shigehara, K. Synthesis of properties of conjugated poly(1,8-carbazole)s. Macromolecules 2009, 42, 8172-8180.

28. Morin, J.-F.; Leclerc, M.; Adès, D.; Siove, A. Polycarbazoles: 25 years of progress. Macromol. Rapid Commun. 2005, 26, 761-778.

29. Halkyard, C.E.; Rampey, M.E.; Kloppenburg, L.; Studer-Martinez, S.L.; Bunz, U.H.F. Evidence of aggregate formation for 2,5-dialkylpoly( $p$-phenyleneethynylenes) in solution and thin films. Macromolecules 1998, 31, 8655-8659.

30. Bouchard, J.; Belletête, M.; Durocher, G.; Leclerc, M. Solvatochromic properties of 2,7-carbazole-based conjugated polymers. Macromolecules 2003, 36, 4624-4630.

31. Liu, R.-R.; Lin, Z.-Q.; Shi, N.-E.; Zhao, J.-F.; Hou, X.-Y.; Qian, Y.; Xie, L.-H.; Huang, W. Synthesis and characterization of 1,8-carbazole-based $\pi$-conjugated copolymer with zigzagged conformation for stable deep-blue emission. Chem. Lett. 2010, 39, 522-523.

32. Zhao, T.; Liu, Z.; Song, Y.; Xu. W.; Zhang, D.; Zhu, D. Novel diethynylcarbazole macrocycles: synthesis and optoelectronic properties. J. Org. Chem. 2006, 71, 7422-7432.

33. Iraqi, A.; Wataru, I. 3,6-Linked 9-alkyl-9H-carbazole main-chain polymers: Preparation and properties. J. Polym. Sci. A 2004, 42, 6041-6051.

34. Eaton, D.F. Reference materials for fluorescence measurement. Pure Appl. Chem. 1988, 60, 1107-1114.

(C) 2010 by the authors; licensee MDPI, Basel, Switzerland. This article is an Open Access article distributed under the terms and conditions of the Creative Commons Attribution license (http://creativecommons.org/licenses/by/3.0/). 